Gut, 1965, 6, 296

\title{
Selective vagal effects on the intestinal phase of gastric secretion
}

\author{
MICHAEL D. MIDDLETON ${ }^{1 *}$, KEITH A. KELLY, LLOYD M. NYHUS, AND \\ HENRY N. HARKINS \\ From the Department of Surgery, University of Washington \\ School of Medicine, Seattle, Washington
}

\begin{abstract}
EDITORIAL SYNOPSIS Evidence is presented from studies in dogs with Heidenhain pouches and with the remainder of the stomach removed that total vagotomy increases the response of the pouch to the intestinal phase of acid secretion. The relative importance of the anterior and posterior vagal trunks has been studied by dividing these separately. Of the various theoretical explanations for this finding, the authors favour a prolongation of the release of the intestinal humoral-stimulating agent in the vagotomized intestine as a major factor.
\end{abstract}

The intestinal phase of gastric secretion was first described by Leconte in 1900 , but Pavlov, in 1910 , claimed prior recognition for himself and his co-workers. The understanding of this phase has progressed but slowly since these initial observations, most workers being more concerned with the gastric phase itself and the direct effects of the vagus on the stomach. This lack of interest has been largely due to the minor quantitative role which the intestinal phase is thought to play in the overall mechanism of gastric secretion (Dragstedt, Oberhelman, Zubiran, and Woodward, 1953). Current surgical procedures for the treatment of duodenal ulcer, notably vagotomy combined with antrectomy, are designed to eliminate these two major phases of gastric secretion. In patients subjected to such procedures the intestinal phase must play an enhanced role in the production of such gastric secretion as remains. It is, therefore, important to obtain a better understanding of the normal physiological mechanisms involved in the intestinal phase of gastric secretion.

Kelly, Nyhus, and Harkins (1964), using a preparation consisting of a total gastrectomy with preservation of the vagus nerves, except for those branches going to the stomach, found a rise in 24-hour acid production from the Heidenhain pouches of dogs after total truncal vagotomy. This experiment provided direct evidence that the vagus nerves influence the intestinal phase of gastric secretion.

'Supported by U.S.P.H.S. grants no. AM-04010 (Secretion Effects) and AM-03898 (Phases of Secretion) from the National Institutes of Health.

*Present address : Royal Infirmary of Edinburgh.
The following experiment was designed to study this effect of the vagus in more detail.

\section{MATERIALS AND EXPERIMENTAL METHOD}

Six mongrel dogs (14 to $20 \mathrm{~kg}$.) were employed. The initial preparation was made in the following manner. The dogs were anaesthetized using intravenous pentobarbital, $30 \mathrm{mg} . / \mathrm{kg}$. intravenously, supplemented, if necessary, with intravenous thiamylal sodium. Adequate ventilation was ensured by the use of a cuffed endotracheal tube connected to a Palmer respirator. The abdomen was entered through a left subcostal incision. A Heidenhain pouch was constructed from the corpus of the stomach in the manner employed in this laboratory (DeVito and Harkins, 1959; Condon and Harkins, 1962). The anterior and posterior vagus nerves were isolated at the region of the oesophageal hiatus and their gastric branches divided. Care was taken to leave intact the hepatic and coeliac branches of these nerves. The stomach thus freed from its vagal connexions was removed entirely and an end-to-end oesophago-duodenal anastomosis was made.

Before closing the abdomen the vagal nerves were inspected carefully, especially the fine ramus of the hepatic branch which supplies the duodenum, to verify that they were intact.

The completed preparation can be summarized briefly as a dog with a total gastrectomy, selective gastric vagotomy, and a Heidenhain pouch. In such a preparation the secretion of acid from the pouch following the ingestion of food occurs as a result of stimulus from the intestinal phase of gastric secretion.

One month was permitted to elapse following operation. Throughout the experiment pouch collections were taken under identical conditions in the following manner. 
STAGE I Food was withheld for 24 hours but water was allowed ad libitum; the dogs were then placed in Pavlov stands. Pouch secretions were collected by gravity in a $15-\mathrm{ml}$. graduated test tube which was attached to the cannula. Ten ml. of $0.005 \mathrm{~N} \mathrm{HCl}$ was added to each collection so that an adequate volume was available for titration. A $5 \mathrm{ml}$. aliquot was then taken and titrated against $0.01 \mathrm{~N} \mathrm{NaOH}$ to an end-point $p \mathrm{H} \cdot 7$, using a Fisher automatic titremeter. The total milliequivalents of acid in each collection were then calculated, subtracting the value obtained from the milliequivalents of acid present in the diluent. Collections were made initially at 15 -minute intervals to confirm that the dogs were not secreting acid. They were then fed a standard meal composed of $200 \mathrm{~g}$. strained beef liver (Gerber's, Armour, Ltd.). Collections from the pouches were then taken at half-hour intervals for the following six hours.

The experiment was discontinued if the dog was secreting acid before feeding or if it vomited after the meal. Ten such observations were completed on each dog before progressing to the second stage in the experment.

STAGE II The dogs were then separated into two groups. Group A (two dogs) was subjected to a transthoracic anterior vagotomy; Group B (four dogs) to a transthoracic posterior vagotomy. The exact point of division of the vagal nerves in the chest is depicted in Figure 1. A period of three weeks was allowed in each dog for recovery after the partial vagotomy, and pouch secretions were again collected in the manner already described. Ten such observations were made for each dog.

STAGE III Both groups then had their vagotomies completed using the transthoracic approach. Following a three-week recovery period the secretions from the pouches, in response to feeding, were again collected 10 times for each dog.

All dogs were then necropsied, the completeness of the transthoracic vagotomies verified, and the course of the vagus nerves traced to ascertain that selective gastric vagotomy had indeed been performed.

\section{RESULTS}

The total acid output obtained in the six hours

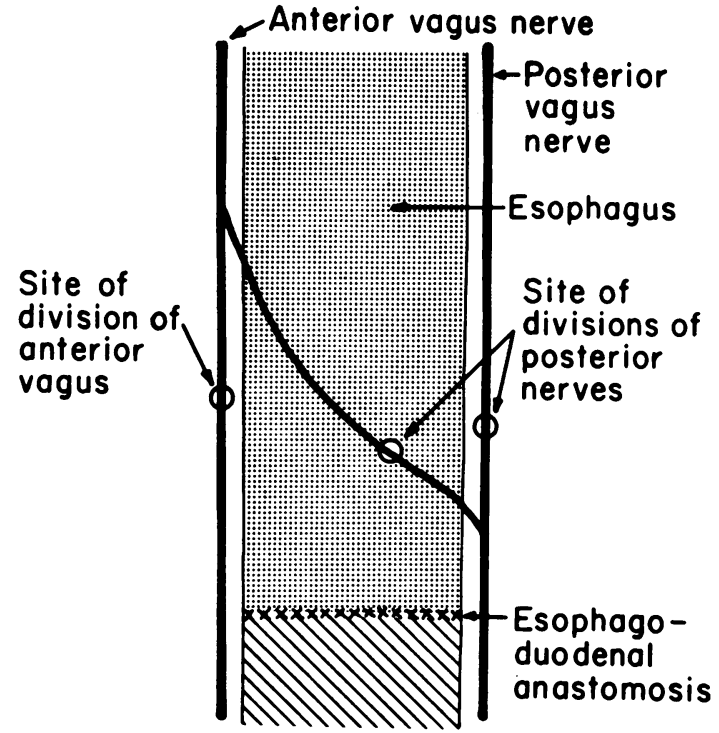

FIG. 1. Diagrammatic representation of the arrangement of the vagal nerves around the lower oesophagus, demonstrating the sites of division of these nerves in stages II and III of the experiment.

after feeding on each occasion was expressed in milliequivalents. The mean value of the 10 separate observations which were made for each stage of the experiment was calculated. A comparison of the average acid output for each stage was made and the statistical significance of the different values obtained was determined by using Student's t test (Fisher, 1950). The results are presented in Table I.

A graphic representation of the changes which occurred is shown in Fig. 2 where the mean value for the first stage is expressed as $100 \%$, and the results of stages II and III are expressed as a percentage of stage I.

It is clearly shown that in group A anterio-

TABLE I

EFFECT OF SELECTIVE VAGAL DENERVATION ON THE MEAN OUTPUT OF ACID IN MILLIEQUIVALENTS FROM HEIDENHAIN POUCHES IN DOGS WITH TOTAL GASTRECTOMY AND OESOPHAGODUODENOSTOMY

\begin{tabular}{|c|c|c|c|c|c|c|c|}
\hline \multirow[t]{3}{*}{$\begin{array}{l}\text { Dog } \\
\text { No. }\end{array}$} & \multirow{3}{*}{$\begin{array}{l}\text { Stage I: Vagally } \\
\text { Innervated } \\
\text { Abdominal } \\
\text { Viscera }\end{array}$} & \multicolumn{2}{|c|}{$\begin{array}{l}\text { Stage II: Partial Visceral Vagal } \\
\text { Denervation }\end{array}$} & \multirow{3}{*}{$\begin{array}{l}\text { Stage III: Total } \\
\text { Vagal Visceral } \\
\text { Denervation }\end{array}$} & \multicolumn{3}{|c|}{ Significance of Difference Between Stages ${ }^{1}$} \\
\hline & & \multirow{2}{*}{$\begin{array}{l}\text { Anterior } \\
\text { Vagotomy }\end{array}$} & \multirow{2}{*}{$\begin{array}{l}\text { Posterior } \\
\text { Vagotomy }\end{array}$} & & Stage I/Stage II & Stage I/Stage III & Stage II/Stage III \\
\hline & & & & & $p$ & $p$ & $p$ \\
\hline $\begin{array}{l}\text { K63 } \\
\text { D6 } \\
\text { D5 } \\
\text { K81 } \\
\text { K64 } \\
\text { D11 }\end{array}$ & $\begin{array}{ll}1.688 & ( \pm 0.2177) \\
1.541 & ( \pm 0.1590) \\
1.046 & ( \pm 0.1426) \\
0.6536 & ( \pm 0.0721) \\
0.478 \quad( \pm 0.1335) \\
0.4795( \pm 0.0692)\end{array}$ & $\begin{array}{l}1.5529( \pm 0.1649) \\
1.4315( \pm 0.2058) \\
- \\
- \\
-\end{array}$ & $\begin{array}{l}\overline{-} \\
\overline{3.5654}( \pm 0.4006) \\
1.050( \pm 0.1025) \\
0.2825( \pm 0.001) \\
1.4228( \pm 0.1802)\end{array}$ & $\begin{array}{l}3.243( \pm 0.5305) \\
3.43 \quad( \pm 0.4506) \\
5.9325( \pm 1.2178) \\
2.6792( \pm 0.3394) \\
0.6851( \pm 0.1476) \\
2.052 \quad( \pm 0.218)\end{array}$ & $\begin{array}{c}0.5263<0.50 \\
0.4438<0.50 \\
6.2624<0.001 \\
3.388<0.01 \\
4.7566<0.001 \\
5.1486<0.001\end{array}$ & $\begin{aligned} & 2.8589<0.02 \\
& 4.169<0.001 \\
& 8.9357<0.001 \\
& 6.4383<0.001 \\
& 1.100<0.50 \\
& 7.2532<0.001\end{aligned}$ & $\begin{array}{l}3.3374<0.001 \\
4.2539<0.001 \\
2.7365<0.02 \\
4.8433<0.001 \\
2.8169<0.02 \\
2.3433<0.05\end{array}$ \\
\hline
\end{tabular}

${ }^{1}$ Ten feeding tests were performed on each dog in each stage of the experiment except DS in stage III which completed only three tests. 


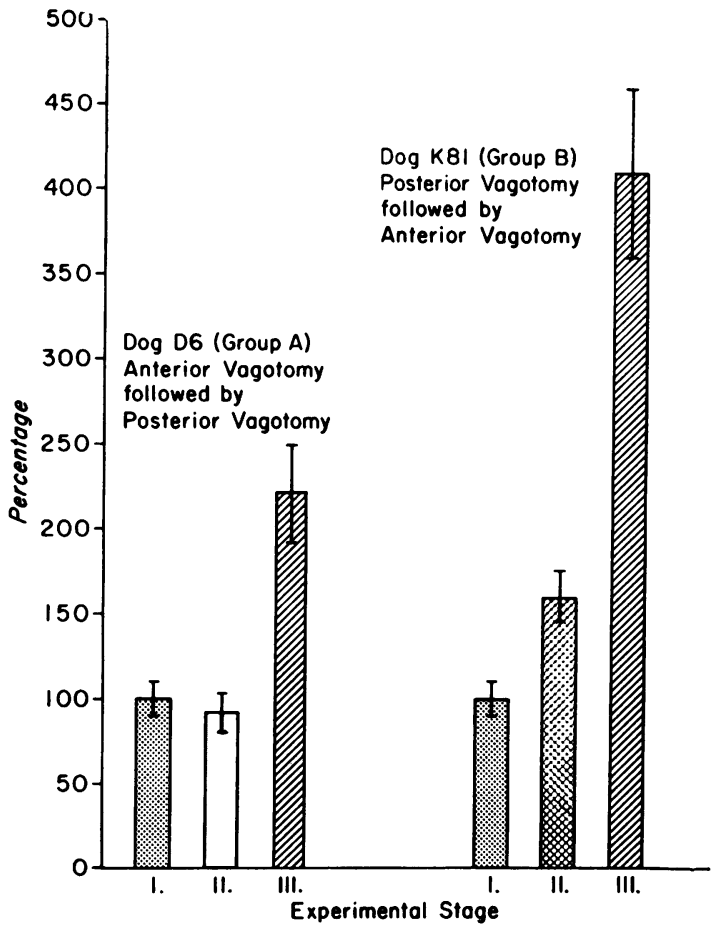

FIG. 2. Graphic representation of the changes in acid output from the gastric pouches in response to feeding. One representative dog from each group is demonstrated. The mean value obtained for stage I is expressed as $100 \%$, and the values for stages II and III are expressed as a percentage of stage I. Standard deviations are included as an index of the significance of the changes. vagotomy alone had no significant effect on acid output, but subsequent posterior vagotomy caused a significant increase.

In group B a small but significant increase in acid output followed posterior vagotomy and this increase was further raised by division of the anterior vagus nerve.

Figure 3 shows the average pattern of secretion in the same dogs shown in Fig. 2, which are taken as representative of each group. The time of onset of secretion following the ingestion of the test meal in each dog varied between half-an-hour to one hour, and the peak value obtained occurred between one-and-a-half to two hours. However, the secretory pattern in each dog was remarkably constant during each stage of the experiment. Vagotomy did not delay the onset of secretion in any dog nor did it alter the timing of the peak output of acid. In group A, anterior vagotomy did not alter the secretory pattern, subsequent total vagotomy caused an increase in the peak value, and the duration of secretion was prolonged. In group B, posterior vagotomy caused no rise in peak value but showed a prolonged duration of secretion, accounting for the raised total output of acid after feeding. The addition of total vagotomy in stage III caused an elevation of peak value and a more pronounced prolongation of secretion similar to the results found in stage III group A.

Dog D5 only completed three valid runs in the third stage. Before further observations could be made he developed a pulmonary infection and died. The results of these runs are, however, in agreement

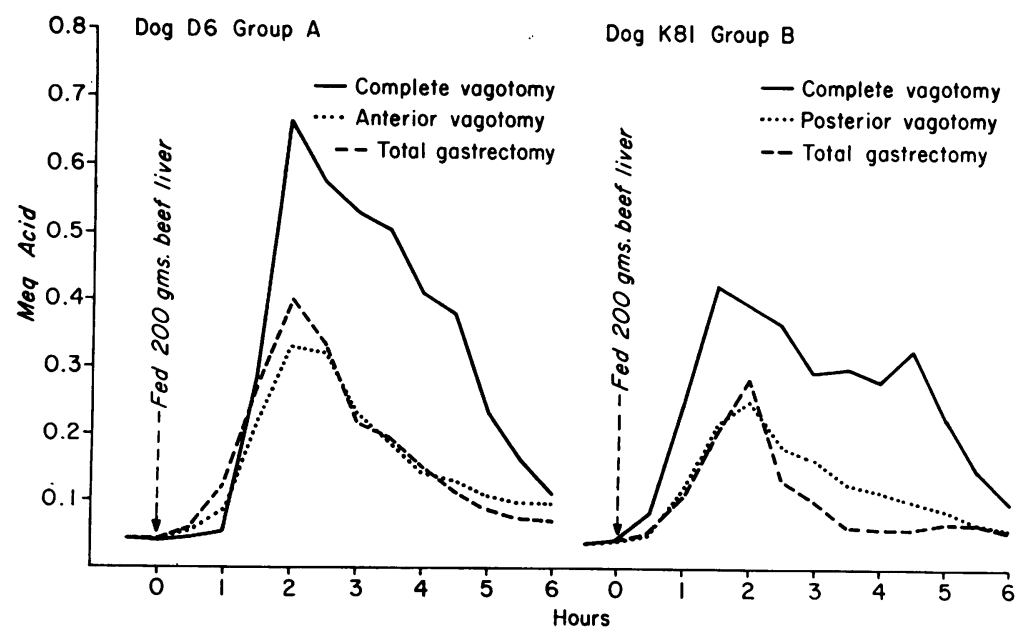

FIG. 3. Graphic representation of the average half-hourly yields of acid which were obtained in response to feeding in each experimental stage. The same two dogs as illustrated in Fig. 2 are shown. These graphs demonstrate the changes which occur in the secretory pattern following anterior or posterior vagotomy and complete vagotomy. 


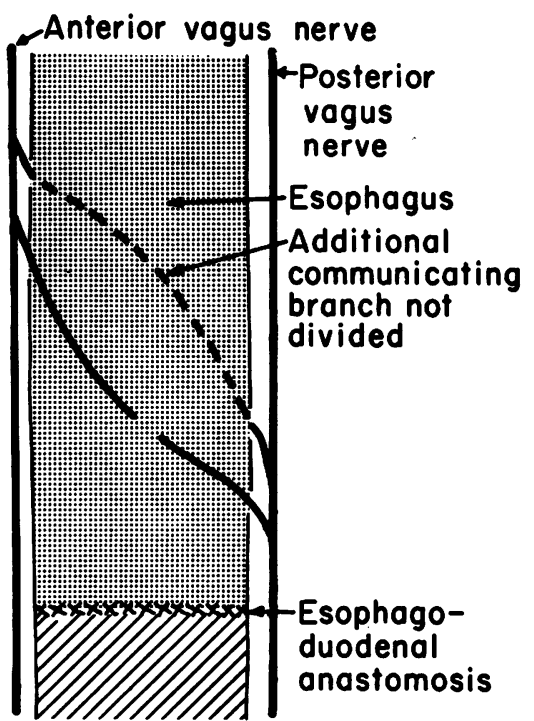

FIG. 4. Diagram of the findings at necropsy on dog K64 demonstrating the anomalous communicating branch between the anterior and posterior vagal nerves which escaped division.

with the results of the other dogs in group B and are significant (Table I).

At necropsy, in five of the dogs, it was confirmed that a selective gastric vagotomy and subsequent transthoracic vagotomies had been performed.

Dog K64, whose acid output differed from the rest of the group, was found at necropsy to have an anomalous double connexion between the anterior and posterior vagus nerves around the lower oesophagus, which had been left intact, and this condition is depicted in Figure 4. An incomplete vagotomy had been performed; the first operation did not, in fact, deprive the dog of all fibres to the posterior nerve. The anterior vagotomy deprived the dog of all the vagal fibres except those in the undivided anomalous branch from the anterior nerve supplying the posterior nerve. Even this small contribution appears to have been sufficient to prevent a change in acid output.

Throughout the experiment the dogs appeared healthy and ate their food avidly. After recovering from the initial total gastrectomy, the dogs soon found their own pattern of eating and although two preferred to eat slowly the others gulped their food at a surprising rate and did not vomit it back.

The weight loss throughout the experiment was similar to that found by Kelly, Nyhus, and Harkins (1964).
DISCUSSION

These findings clearly show that vagotomy increases the effectiveness of the intestinal phase of the gastric secretory mechanism in its ability to stimulate acid secretion from Heidenhain pouches in dogs. This is in agreement with the conclusions of Dragstedt et al. (1960), Kelly et al. (1964), and Landor (1964) in their 24-hour collection studies.

In addition, the relative role played by the anterior and posterior vagal nerves has been studied. This has demonstrated that division of the anterior nerve alone had no significant effect on acid output from the pouch, but subsequent transection of the posterior nerve caused a significant increase in acid secretion. Posterior vagotomy alone caused a significant increase in pouch acid output which was further increased when anterior vagotomy was added. A possible explanation for these results may be postulated on a purely anatomical basis. Stavney, Kato, Griffith, Nyhus, and Harkins(1963), in a study of the motility changes in the gut following vagotomy, concluded that the posterior vagus nerve innervated the entire small intestine and the ascending colon, but the anterior nerve innervated only the duodenum and did not extend its influence below the ligament of Treitz. Thus in the experiment reported herein, when anterior vagotomy alone was performed, there was still vagal innervation through the posterior nerve to the entire small intestine, and no change in acid secretion resulted. Posterior vagotomy alone vagally denervated the small intestine distal to the duodenum and caused an increase in acid secretion. The addition of anterior vagotomy caused the duodenum to be completely denervated, and this resulted in a further increase in pouch acid output. This finding demonstrates that the increase in pouch acid secretion following vagotomy is caused by factors operating both in the duodenum and in the more distal bowel, and these effects are additive.

The mechanism behind these observations is not clearly understood. A lowering of gastric acidity causing a decreased duodenal inhibition, as suggested by Dragstedt et al. (1960), may well be a factor in dogs which have the duodenum in direct continuity with the stomach. This concept cannot be entertained in our experiment, for the stomach was totally removed in every dog.

Several authors (Rudick and Hutchison, 1964; Cox, Doherty, and Kerr, 1958) have demonstrated changes in the extrahepatic biliary apparatus following truncal vagotomy. The gall bladder volume is doubled and the rate of emptying is decreased. Menguy (1960), using rats, showed that fat does not release enterogastrone unless bile is present in the small intestine. This alteration of the biliary 
mechanism would not seem to play a part since the biliary tree is innervated from the anterior vagus, and anterior vagotomy alone does not alter acid output from the Heidenhain pouch. On the occasions when the dogs vomited after feeding, bile was always in evidence even shortly after the administration of food.

Derangement of pancreatic function has been shown to alter gastric secretion of acid (Mason, Eigenbrodt, Oberhelman, and Nelsen, 1962; Hein, Silen, and Harper, 1962), but this factor cannot be evaluated in this experimental model.

It has been suggested by Kelly et al. (1964) that intestinal stasis and distension following vagotomy cause delay in the passage of food and thus prolong stimulation of the release of intestinal gastrin. Our results are consistent with this theory. Figure 3 illustrates average patterns of acid output in the three stages of the experiment. There is no delay in the production of acid, and the peak acid output after feeding occurs at the same interval of time before and after vagotomy. The acid production is continued for a longer period of time following vagotomy, which would lend support to the concept of intestinal stasis as an important factor. The peak acid production is, however, considerably higher following vagotomy. This would suggest that either more intestinal gastrin per unit time is produced following vagotomy, or the release of enterogastrone is impaired and intestinal gastrin is, therefore, acting unencumbered by a simultaneous release of enterogastrone. Payne and Kay (1962) refer to the permissive action of the vagus in the release of antral gastrin, and it is tempting to postulate that the vagus is in some way permissive to the release of enterogastrone. Most probably this effect of the vagus is a summation of several factors, with stasis and enterogastrone release playing a large part.

\section{SUMMARY}

The effect of vagotomy on the intestinal phase of gastric acid secretion was evaluated in dogs, which had been prepared with Heidenhain pouches, total gastrectomy, selective gastric vagotomy, and oesophagoduodenostomy.

Our results confirmed previous reports demonstrating that vagotomy increases the gastric acid secreted in response to the intestinal phase of gastric secretion, and also disclosed the relative influence of the anterior and posterior vagal nerves in this increase. The effect of vagotomy was not due to decreased acid inhibition from the duodenum because no acid entered the duodenum in this preparation. The exact mechanism of this phenomenon is not known, but the possible roles of intestinal stasis and decreased enterogastrone release were discussed.

\section{REFERENCES}

Condon, R. E., and Harkins, H. N. (1962). An improved cannula for experimental gastric pouches. Surgery, 52, 363-365.

Cox, H. T. Doherty, J. F., and Kerr, D. F. (1958). Changes in the gallbladder after elective gastric surgery. Lancet, 1, 764-766.

DeVito, R. V., and Harkins, H. N. (1959). Techniques in Heidenhain pouch experiments. J. appl. Physiol., 14, 138-139.

Dragstedt, L. R., Oberhelman, H. A. Jr., Zubiran, J. M., and Woodward, E. R. (1953). Antrum motility as a stimulus for gastric secretion. Gastroenterology, 24, 71-78.

_- II, Johnson, A. N. Jr., Singer, E. R., and Oberhelman, H. A. Jr. (1960). The effect of vagotomy on the intestinal phase of gastric secretion. Surg. Forum, 11, 336-338.

Fisher, R. A. (1950). Statistical Methods for Research Workers, 11th ed., p. 99. Oliver and Boyd, Edinburgh.

Hein, M. F., Silen, W., and Harper, H. A. (1962). Studies on the mechanism of gastric hypersecretion following complete ligation of the pancreatic ducts. Surg. Forum, 13, 294-296.

Kelly, K. A., Nyhus, L. M., and Harkins, H. N. (1964). The vagal nerve and the intestinal phase of gastric secretion. Gastroenterology, 46, 163-166.

Landor, J. H. (1964). The effect of extragastric vagotomy on Heidenhain-pouch secretion in dogs. Amer. J. dig. Dis., 9, 256-262.

Leconte, P. (1900). Fonctions gastro-intestinales. Etude physiologique. Cellule, 17, 283-321.

Mason, G. R., Eigenbrodt, E. H., Oberhelman, H. A. Jr., and Nelsen, T. S. (1962). The effect of pancreatic inflammation on gastric secretion. Surg. Forum, 13, 297-298.

Menguy, R. (1960). The role of bile in gastric inhibition by fat in the small bowel. Ibid., 10, 164-167.

Pavlov, I. P. (1910). The Work of the Digestive Glands, 2nd, ed. translated by W. H. Thompson, p. 114. Griffin, London.

Payne, R. A., and Kay, A. W. (1962). The effect of vagotomy on the maximal acid secretory response to histamine in man. Clin. Sci., 22, 373-382.

Rudick, J., and Hutchison, J. S. F. (1964). Effects of vagal-netve section on the biliary system. Lancet, 1, 579-581.

Stavney, L. S., Kato, T., Griffith, C. A., Nyhus, L. M., and Harkins, H. N. (1963). A physiologic study of motility changes following selective gastric vagotomy. J. surg. Res., 3, 390-394. 